\title{
A NEW SPECIES OF CHARTOCERUS (HYMENOPTERA: CHALCIDOIDEA: SIGNIPHORIDAE) FROM WEST BENGAL, INDIA
}

\author{
Mohammad Hayat \\ Department of Zoology, Aligarh Muslim University, Aligarh, Uttar Pradesh 20002, India. \\ Email: mohd_hayat@rediffmail.com
}

\begin{abstract}
A new species of the signiphorid genus Chartocerus Motschulsky is described and illustrated.

Keywords

Chalcidoidea, Chartocerus, Hymenoptera, India, new species, Signiphoridae
\end{abstract}

\begin{abstract}
Abbreviations
M2b - Second seta of the marginal vein along its anterior margin M6 - Second seta of the marginal vein along its posterior margin TI - TVII - Gasteral terga 1-7
\end{abstract}

\section{Introduction}

Signiphoridae is a small family of the Chalcidoid Hymenoptera, consisting of four genera and 71 species, distributed worldwide. Members of this family are mostly hyper-parasitoids parasitizing other primary hymenopteran, mostly chalcidoid, parasitoids, although a few species have been recorded as primary parasitoids (Woolley, 1988, for a review). From India only two genera, Thysanus Walker and Chartocerus Motschulsky, are known. The former represented by a single species, T. ater Haliday; and the latter by seven species (Hayat, 1970; 1976). This paper describes an interesting species of Chartocerus from material collected from West Bengal (India) by Dr. B.K. Das.

\section{Chartocerus bengalensis sp. nov.}

(Figs. 1-10)

\section{Material examined}

Holotype: Female (on slide under two coverslips), 25.iii.2000, Kalyani, West Bengal, India, ex Aspidiotus sp. on Mangifera indica, coll. B.K.Das, deposited in N.P.C., Division of Entomology, I.A.R.I., New Delhi.

Paratypes: Eight females, three males (two females on the same slide with holotype, but under three separate coverslips; one male on a second slide under two coverslips; six females and two males on a third slide under two coverslips), 25.iii.2000, Kalyani, West Bengal, India, ex Aspidiotus sp. on Mangifera indica, coll. B.K.Das. Two female paratypes deposited in N.P.C., Division of Entomology, I.A.R.I., New Delhi; rest of the material in Hayat collection.

\section{Host}

Aspidiotus sp. on Mangifera indica.

\section{Distribution}

India: Kalyani, West Bengal

\section{Etymology}

The species name is derived from the name of the Indian state from where the specimens were collected.

\section{Diagnostic features}

Female: Length, $0.36-0.40 \mathrm{~mm}$. Head with vertex and a curved band on occiput above foramen, dark brown, rest of head yellow to pale brownish-yellow, with a black patch between toruli and mouth margin; thorax yellow, with pronotum, anterior half or so, except sides of mesoscutum, propodeum except sides, and gaster completely, dark brown to nearly black. Antenna 

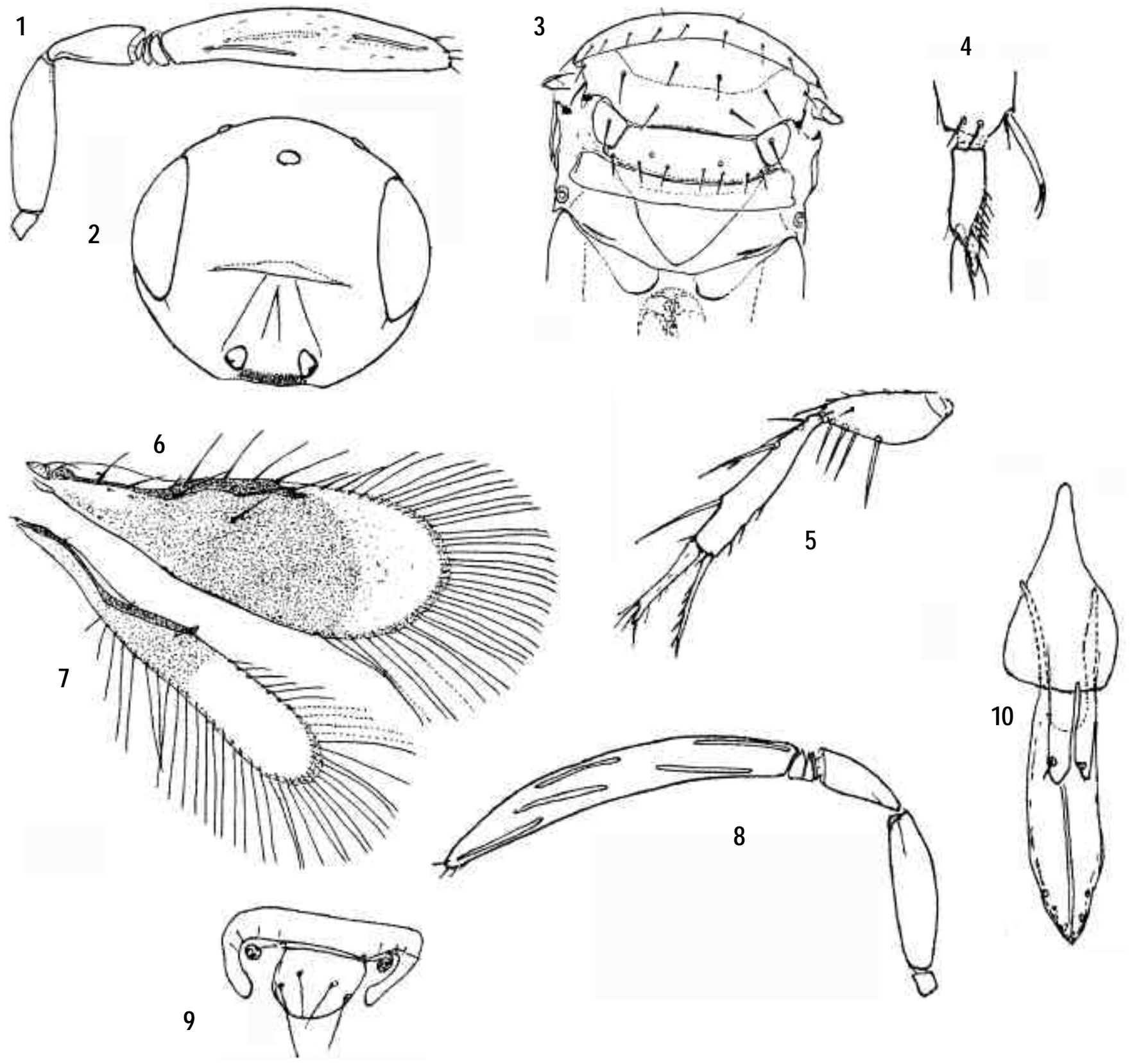

Figures 1-10. Chartocerus bengalensis sp. nov.

1-7 - Female: 1 - Antenna; 2 - Head frontal; 3 - Thorax dorsal; 4 - Fore tibial apex and basitarsus;

5 - Mid femur, tibia and basitarsus; 6 - Fore wing; 7 - Hind wing; 8-10 - Male: 8 - Antenna; 9 - Apical terga; 10 - Genitalia 
brownish-yellow. Fore wing infuscate from near base to level with stigmal vein, apically hyaline (Fig. 6); hind wing hyaline, with a faint infuscation in about middle. Legs yellow or brownish-yellow, with hind femora and tibiae infuscate brown.

Head dorsally convex, in front view, almost rounded, nearly as long as broad (44: 47); frontovertex width two-thirds of head width (31: 47) and nearly twice of scape length (31: 17); other details as in Fig. 2; mandible bidentate. Antenna (Fig. 1) with three anelliform funicle segments, third segment larger and longer than the other two.

Thorax (Fig. 3) pronotum, mesoscutum and propodeum with transversely elongate to lineolate-reticulate sculpture; sculpture fine and discernible at higher magnification; mesoscutum with 10 setae; each axilla with one seta, and scutellum with a line of 6-7 setae along posterior margin. Fore wing (Fig. 6) slightly less than $3 \mathrm{x}$ as long as broad, with marginal fringe about fourfifths of wing width; setae M2b, M6 and a discal seta present. Hind wing (Fig. 7) almost parallel-sided, 7x as long as broad; marginal fringe nearly $2 \mathrm{x}$ as long as width of wing. Fore leg spur (Fig. 4) and spines on mid femur and tibia (Fig. 5) characteristic of the genus.

Gaster about as long as thorax (54: 52); terga with setae as follows: TI-IV - each with $1+1$; TV $-3+3$, of which the submedian pair of setae smaller; TVI - one seta just mesad of each spiracle; TVII - 6 setae. Relative measurements (holotype): Ovipositor length, 46; third valvula length, 10. (Mid tibia length, 27; mid basitarsus length, 14; mid spur length, 16).

Male: Similar to female in nearly all the characters, except for the more slender antennal clava (Fig. 8) and the genitalia (Fig. 10). The genitalia are characterized by a short and anteriorly narrowed phallobase; absence of papilliform processes and median denticles; digiti are flat, elongate structures, lacking apical denticles, but each digitus is provided with a short, subapical seta; aedeagus long.

\section{Remarks}

This species is placed in Chartocerus with some hesitation. It has the following characters of Chartocerus: fore tibial spur (=calcar) without a comb of fine setae (Fig. 4); propodeum without a lamelliform process posteriorly (Fig. 3); mid femur with three or four long spines (Fig. 5); and fore wing with setae M2b and M6 (Fig. 6). The characters that are different from Chartocerus are: female funicle with three anelli (Fig. 1); fore wing with a discal seta (Fig. 6); male with an epiproct distinct (Fig. 9). The male genitalia are peculiar in that these lack digital denticles, papilliform processes and median denticles. The phallobase and the digiti are more or less similar to those of males of the aphelinid (Family: Aphelinidae) genera Bardylis Howard and Coccophagoides Girault. In the characters of the male genitalia, presence of an epiproct in males, presence of three anelli forming the funicle in female, and the body colour, the new species differs from all the other Indian species of this genus (Hayat, 1970; 1976). In all the seven Indian species, the body is completely dark brown to black; fore wing without a discal seta; funicle with four anelliform segments; males without an epiproct; and male genitalia are provided with papilliform processes, medial denticles, and each digitus has a robust denticle at apex.

\section{Acknowledgements}

I thank Dr. B.K. Das (Department of Entomology, Bidhan Chander Krishividyalaya, Mohanpur, Nadia, West Bengal) for collecting the specimens, and Prof. T. C. Narendran (Department of Zoology, University of Calicut, Kozhikode) for passing these specimens on to me for study.

\section{References}

Hayat, M. (1970). Studies on the genera of the family Signiphoridae (Hymenoptera: Chalcidoidea) recorded from India. Entomophaga 15: 387-399.

Hayat, M. (1976). Some Indian species of Chartocerus (Hym: Chalcidoidea: Signiphoridae). Oriental Insects 10: 161-164.

Woolley, J.B. (1988). Phylogeny and classification of the Signiphoridae (Hymenoptera: Chalcidoidea). Systematic Entomology 13: 465-501.

\section{Erratum}

In a recent paper (Basha, M.C. and M. Hayat, 2002, Zoos' Print Journal 17(6): 791-794), the authors failed to indicate the location of the holotypes of the two species described. The holotypes of Caenohomalopoda longiclava Basha and Hayat, and of Mahencyrtus adelencyrtoides Basha and Hayat were deposited in the N.P.C., Division of Entomology, I.A.R.I., New Delhi.

\section{Hayat}

